\title{
Adsorption Characteristics of Ammonium Nitrogen and Plant Responses to Biochar Pellet
}

\author{
JoungDu Shin ${ }^{1, *}$, Eunjung Choi ${ }^{1}$, EunSuk Jang ${ }^{1}$, Seung Gil Hong ${ }^{1}$, SangRyong Lee 2 (i) \\ and Balasubramani Ravindran ${ }^{3}$ \\ 1 National Institute of Agricultural Sciences, Rural Development Administration, 166, Nongsaengmyeong-ro, \\ Wanju-gun 55365, Korea; choiej1@rda.go.kr (E.C.); breeze@rda.go.kr (E.J.); dewhong@rda.go.kr (S.G.H.) \\ 2 Department of Agro-Biotechnology \& Convergence, Jeonju University, Jeonju 55069, Korea; \\ soilsang@gmail.com \\ 3 Department of Environmental Energy and Engineering, Kyonggi University, Youngtong-Gu, \\ Suwon 16227, Korea; ravindran@kyonggi.ac.kr or kalamravi@gmail.com \\ * Correspondence: jdshin@rda.go.kr; Tel.: +82-63-238-2494, Fax: +82-63-238-3823
}

Received: 14 March 2018; Accepted: 10 April 2018; Published: 25 April 2018

\begin{abstract}
For feasibility of carbon sequestration as well as in the mitigation of greenhouse gases for application of biochar pellet, this experiment was conducted, focusing on the adsorption characteristics of $\mathrm{NH}_{4}-\mathrm{N}$ on biochar pellet mixed with different ratios of pig manure compost. For $\mathrm{NH}_{4}$-N adsorption on biochar pellets, the loading amount of biochar pellet was $211.5 \mathrm{mg}$ in $50 \mathrm{~mL}$ of aqueous solution, and the adsorption fitted very well with Langmuir isotherm. The maximum adsorption and removal rates were $2.94 \mathrm{mg} \mathrm{g}^{-1}$ and $92.2 \%$, respectively, in the pellet that contained $90 \%$ of biochar. It was also observed, by kinetic models, that $\mathrm{NH}_{4}-\mathrm{N}$ was adsorbed fast on biochar pellet with a combination ratio of 9:1 of biochar pellet/pig manure. It was further observed that the higher the amount of biochar contained in the biochar pellet, the greater the adsorption of $\mathrm{NH}_{4}-\mathrm{N}$. For the plant response observed for lettuce, it was shown that the leaf biomass in plots treated with a 9:1 biochar/pig manure compost increased by approximately 13\% compared with the leaf biomass in plots treated with the compost alone. The leaf biomass of the other treatments was higher than that of the control. This implies that the application of biochar pellets, regardless of the biochar contents, might be useful for soil carbon sequestration and greenhouse gas mitigation for agricultural practices.
\end{abstract}

Keywords: carbon sequestration; ammonium nitrogen; biochar pellet

\section{Introduction}

Biomass is waste materials from agricultural products which includes agricultural residues and forest resources [1]. The byproducts from rural areas are a resource of latent energy; they can cause greenhouse gas emissions as well as agro-environmental problem [2]. MIFAFF [3] estimated that 50 million tons of organic wastes in agriculture are produced out of 80 million tones every year. The use of biomass has not only reduced the environmental problem but has also been able to convert the biomass into value-added products.

Biochar is the residual material obtained by the thermal reaction of biomass under deficiency of oxygen using biomass conversion technology. Biochar from thermal conversion technology has recently attracted attention for its potential ability of carbon sequestration, suggesting the possibility to act against climate changes through the addition of biochar into soil. Biochar's positive effects on the agro-ecosystem have been suggested to derive either from nutrients in the biochar or from its ability to control these nutrients [4]. When biochar is applied to soil, an additional application of fertilizer is still needed to increase crop yield. Many researchers investigated the value-added 
biochar for soil carbon sequestration, which suggested the combination of biochar with composts before soil application [5]. Biochar mixed with sludge composite into landfill was known to apparently decrease nitrogen loss [6]. However, biochar application to soil became challenging because biochar is easily breakable and produces saw dust with low density. Kamman et al. reported a 30\% loss of the biochar by wind-blow during handling and especially a $25 \%$ of biochar lost for spreading of biochar in croplands [7]. In addition, a loss from $20 \%$ to $53 \%$ of biochar was measured as a consequence of runoff during intensive rain falls [8]. However, Shin [9] indicated that the total carbon incorporated by biochar during harvesting periods ranged from $0.96 \%$ to $1.24 \%$, and its cow compost produced the highest levels at $1.24 \%$ in a corn field. It appeared that the total carbon's contents obtained with biochar treatments were higher than those obtained with the compost treatment alone. Therefore, the combination of biochar with organic composts for crop cultivation could be a potential soil carbon sequestration system in agricultural practices. Further, it is necessary to create a value-added biochar that can provide major nutrients to the plants during crop cultivation with a minimum loss. The biochar pellet is a promising way to reduce the handling costs and significantly decreases the loss of biochar during soil incorporation [10]. Biochar pellet has been mostly used as alternative heating material to biomass pellet [11].

For soil incorporation, poultry litter was mixed and slowly pyrolyzed to produce biochar pellet [12]. However, there is not sufficient research on biochar pellet to reduce nutrient release from biochar pellet to the soil throughout crop cultivation thus providing nutrients to crop growth without leaching [13], which can increase a farmer's profit and maximize to the agro-environmental health [14].

Thus, this experiment was conducted to investigate the characteristics of $\mathrm{NH}_{4}-\mathrm{N}$ adsorption of and plant responses to a produced biochar pellet mixed with different ratios of pig manure compost before soil application for carbon sequestration.

\section{Materials and Methods}

\subsection{Raw Materials in the Batch Experiment for Adsorption Determination}

The adsorption study was conducted in deionized water with a biochar pellet mixed with different ratios of pig manure compost. The combination ratios of biochar $(\Phi 0.51 \mathrm{~cm} \times 0.78 \mathrm{~cm})$ and pig manure compost were 9:1, 8:2, 6:4, 4:6, and 2:8. The materials (total weight $=2.5 \mathrm{~kg}$ ) were completely mixed using an agitator for $5 \mathrm{~min}$. Then, while continuously mixing, the combination was sprayed with $1000 \mathrm{~mL}$ of deionized water for $10 \mathrm{~min}$. The biochar pellet was made by pouring the mixture through the machine $(7.5 \mathrm{KW}, 10 \mathrm{HP})$ (Figure 1).

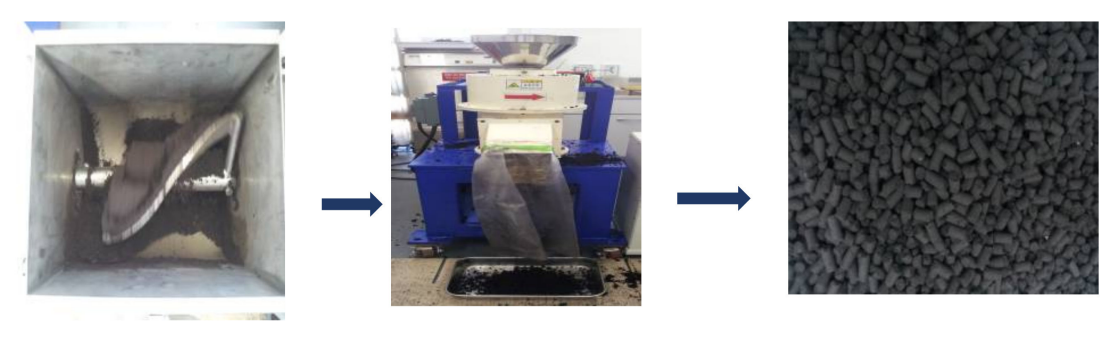

Figure 1. Processing diagram of biochar pellet with different pig compost ratios.

An amount of $50 \mathrm{~mL}$ of deionized water and $211.5 \mathrm{mg}$ of biochar pellet which was estimated from $5500 \mathrm{~kg} \mathrm{ha}^{-1}$ of recommended pig compost input in a corn field were added into $150 \mathrm{~mL}$ of polyethylene bottles, which were tightly capped. All bottles were transferred into a water bath shaker (JP/NTS-3000, Eyela, Kyoto, Japan) for equilibration for 6, 15, 24, 40, 72, 96, 144, 240, and $336 \mathrm{~h}$ at $100 \mathrm{rpm}$ of agitation speed and $25^{\circ} \mathrm{C}$. Biochar from rice hull and pig manure compost was collected 
from a local cooperative union of famers. The chemical properties of the biochar pellets and pig manure compost used are presented in Table 1.

Table 1. Characteristics of the biochar and pig manure compost used ${ }^{1}$.

\begin{tabular}{ccccccc}
\hline & \multirow{2}{*}{$\mathbf{p H}$} & $\mathbf{E C}$ & TC & TOC & TIC & TN \\
\cline { 3 - 7 } & & $\left.\mathbf{( d S ~ m ~}^{-\mathbf{1}}\right)$ & \multicolumn{4}{c}{$\mathbf{\%}$} \\
\hline Biochar & $9.78(1: 20)$ & 16.53 & 56.6 & 52.3 & 4.2 & 0.20 \\
Pig manure compost & $8.77(1: 5)$ & 3.40 & 28.9 & 25.9 & 3.0 & 2.91 \\
\hline
\end{tabular}

${ }^{1}$ TC: Total carbon, TOC: Total organic carbon, TIC: Total inorganic carbon, and TN: Total nitrogen.

\subsection{Adsorption and Removal Rates}

The biochar pellets consisted of different ratio of pig manure compost. For the adsorption rate of $\mathrm{NH}_{4}-\mathrm{N}$ to biochar pellet, the $\mathrm{NH}_{4}-\mathrm{N}$ concentrations from different masses of pig manure composts and retention times $\left(6-336 \mathrm{~h}\right.$ ) were calculated from desorption models of $\mathrm{NH}_{4}-\mathrm{N}$ in the pig manure compost (Table 2). On the basis of the data from a batch scale experiment, estimated releasing models of $\mathrm{NH}_{4}-\mathrm{N}$ in the different loading ratios of pig manure composts (0.1-1.5 g) were derived. From these equations, the released amount of $\mathrm{NH}_{4}-\mathrm{N}$ from each mass of pig manure compost could be calculated, and then these equations were used for normalizing the $\mathrm{NH}_{4}-\mathrm{N}$ contents in different ratios of biochar pellet to determine the releasing $\mathrm{NH}_{4}-\mathrm{N}$ concentrations from biochar pellets with different retention times.

Table 2. Estimated releasing models of $\mathrm{NH}_{4}-\mathrm{N}$ in the pig manure compost with different retention times and input amounts.

\begin{tabular}{ccc}
\hline Retention Times (h) & Linear Equations & $\boldsymbol{R}^{\mathbf{2}}$ \\
\hline 6 & $\mathrm{Y}=23.57 \mathrm{X}+7.652$ & $0.972^{* *}$ \\
15 & $\mathrm{Y}=30.19 \mathrm{X}+9.396$ & $0.988^{* *}$ \\
24 & $\mathrm{Y}=30.37 \mathrm{X}+9.531$ & $0.986^{* *}$ \\
40 & $\mathrm{Y}=34.36 \mathrm{X}+11.166$ & $0.965^{* *}$ \\
72 & $\mathrm{Y}=38.50 \mathrm{X}+10.752$ & $0.979^{* *}$ \\
96 & $\mathrm{Y}=39.11 \mathrm{X}+11.714$ & $0.989^{* *}$ \\
144 & $\mathrm{Y}=42.37 \mathrm{X}+12.709$ & $0.976^{* *}$ \\
240 & $\mathrm{Y}=55.16 \mathrm{X}+17.575$ & $0.953^{* *}$ \\
336 & $\mathrm{Y}=54.63 \mathrm{X}+24.034$ & $0.937^{* *}$ \\
\hline
\end{tabular}

Adsorption amounts and removal rates of the biochar pellets were calculated using these data by applying Equations (1) and (2).

$$
\begin{gathered}
\mathrm{q}_{\mathrm{t}}=\frac{\left(\mathrm{C}_{0}-\mathrm{C}_{\mathrm{t}}\right) \mathrm{V}}{\mathrm{W}} \\
\text { \% Removal }=\frac{\left(\mathrm{C}_{0}-\mathrm{C}_{\mathrm{t}}\right)}{\mathrm{C}_{0}} \times 100
\end{gathered}
$$

where $\mathrm{C}_{0}$ is the initial concentration, and $\mathrm{C}_{\mathrm{t}}\left(\mathrm{mg} \cdot \mathrm{L}^{-1}\right)$ is the equilibrium concentration of $\mathrm{NH}_{4}-\mathrm{N}$ in solution; $\mathrm{q}_{\mathrm{t}}\left(\mathrm{mg} \cdot \mathrm{L}^{-1}\right)$ is the amount of $\mathrm{NH}_{4}-\mathrm{N}$ adsorbed at equilibrium, $\mathrm{V}(\mathrm{L})$ is the mass of solution, and $\mathrm{W}(\mathrm{g})$ is the weight of the biochar pellet.

\subsection{Langmuir Isothermal}

An adsorption isotherm characterizes the surface area between adsorbent and solution when the adsorption equilibrium is reached at a constant temperature and provides the parameters for optimizing the adsorption in a batch scale. The Langmuir isotherm model describes the absorption 
capacity of a monolayer formed between a homogeneous surface area and the adjacent adsorbates [15]. The Langmuir isotherm is derived as:

$$
\frac{1}{\mathrm{C}_{\mathrm{e}}}=\mathrm{bq}_{\mathrm{m}} \frac{1}{\mathrm{q}_{\mathrm{e}}}-\mathrm{b}
$$

where $\mathrm{q}_{\mathrm{e}}(\mathrm{mg} / \mathrm{L})$ is $\mathrm{NH}_{4}-\mathrm{N}\left(\mathrm{mg} \mathrm{g}^{-1}\right)$ adsorbed at equilibrium, $\mathrm{q}_{\mathrm{m}}$ is the maximum monolayer adsorption capacity, $\mathrm{b}$ is an empirical constant representing the monolayer adsorption capacity, and $\mathrm{C}_{\mathrm{e}}$ is the concentration of $\mathrm{NH}_{4}-\mathrm{N}\left(\mathrm{mg} \mathrm{g}^{-1}\right)$ in the biochar pellet at equilibrium; $1 / \mathrm{C}_{\mathrm{e}}$ and $1 / \mathrm{q}_{\mathrm{e}}$ were calculated from the plot, with a straight line with slop yield $\mathrm{q}_{\mathrm{m}}$ and $\mathrm{b}$. In Langmuir isotherm model, the adsorption type is classified by a dimensionless constant factor $r$ which is given by the below equation:

$$
\mathrm{R}_{\mathrm{L}}=\frac{1}{1+\mathrm{bC}_{0}}
$$

where $C_{0}$ is the initial adsorbate concentration.

\subsection{Kinetic Models}

To explain the adsorption kinetics of $\mathrm{NH}_{4}-\mathrm{N}$ on a biochar pellet, kinetic models [16] were employed.

$$
\begin{gathered}
\ln \left(\mathrm{q}_{\mathrm{e}}-\mathrm{q}_{\mathrm{t}}\right)=\ln \mathrm{q}_{\mathrm{e}}-\mathrm{K}_{1} \mathrm{t} \\
\frac{\mathrm{t}}{\mathrm{q}_{\mathrm{t}}}=\frac{1}{\mathrm{~K}_{2} \mathrm{q}_{\mathrm{e}}^{2}}+\frac{1}{\mathrm{q}_{\mathrm{e}}} \mathrm{t}
\end{gathered}
$$

where $\mathrm{q}_{\mathrm{e}}\left(\mathrm{mg} \cdot \mathrm{g}^{-1}\right)$ is the quantity of $\mathrm{NH}_{4}-\mathrm{N}$ adsorbed at equilibrium, $\mathrm{q}_{\mathrm{t}}$ is the absorbed amount at a given interval $(t)$, while $k_{1}$ and $k_{2}$ are constant rates calculated from the straight-line plot of Equations (5) and (6) for the pseudo-first- and second-order models, respectively. In

$$
\mathrm{h}=\mathrm{K}_{2} \mathrm{q}_{\mathrm{e}}^{2}
$$

$\mathrm{h}$ is the initial absorbed amount $\left(\mathrm{mg} \mathrm{g}^{-1} \mathrm{~min}^{-1}\right)$ calculated from (7) [17].

\subsection{Chemical Analysis}

The $\mathrm{pH}$ and EC (electrical conductivity) of the biochar pellet were measured using a $\mathrm{pH} / \mathrm{EC}$ meter (Orion 4 star, Thermo Scientific, Singapore) at a 1:20 solid / water ratio (biochar:de-ionized $\mathrm{H}_{2} \mathrm{O}$ ) after shaking for $30 \mathrm{~min}$ in a water bath (JP/NTS-3000, Eyela, Kyoto, Japan) at $140 \mathrm{rpm}$. The analytical soil and biochar chemical properties, as TC and TOC, were analyzed by a TOC analyzer (Elementar Vario EL II, Hanau, Germany). The combustion temperature was $950{ }^{\circ} \mathrm{C}$, with tungsten oxide $\left(\mathrm{WO}_{3}\right)$ used as the catalyst. Thus, TC contents were obtained. The whole samples from the absorption experiment were filtered through filter paper Whatman No. 2, and the filtrated solutions were calorimetrically analyzed to measure $\mathrm{NH}_{4}-\mathrm{N}$, using a UV spectrophotometer (ST-Ammonium, C-Mac, Dae-Jen, Korea) by monitoring the adsorption at $655 \mathrm{~nm}$.

\subsection{Lettuce Cultivation}

For a bioassay test with the biochar pellets, lettuce seeds were sowed in a nursery plate with peat moss in the glass. The crop used was lettuce (Lactuca sativa L., cv. 'Romaine'). The plants were transplanted into the pots by inserting the nursery bed materials which were mixed with rice and the horticultural seed bed (1:4 ratio) 30 days after seedling. The treatments consisted of a control represented by a pig manure compost consisting of $100 \%$ of pig manure compost pellet, and different combinations of biochar pellets, i.e., 2:8, 4:6, 8:2, and 9:1 Biochar/pig manure compost.

The pot size was $\Phi 18 \times 30 \mathrm{~cm}$, and the loading amount of nursery bed was $2.25 \mathrm{~kg}$ per pot. The amounts of fertilizer and pig manure compost applied were $70-30-36 \mathrm{~kg} \mathrm{ha}^{-1}$ (N-P-K) and 
$3300 \mathrm{~kg} \mathrm{ha}^{-1}$, respectively, the application amount recommended for lettuce culture. The application rate of the biochar pellet was $6.6 \mathrm{~g} \mathrm{pot}^{-1}$ regardless of the mixed ratio and based on the recommended amounts of pig manure compost to be applied $\left(3300 \mathrm{~kg} \mathrm{ha}^{-1}\right)$ for lettuce culture. The drip irrigation was set at $2 \mathrm{~min}$ for irrigation period, done three times per day. The chemical properties of the nursery bed materials used are presented in Table 3. For the bioassay test, the total yield was measured during the growing period.

Table 3. Characteristics of the nursery bed materials for lettuce cultivation ${ }^{1}$.

\begin{tabular}{ccccc}
\hline pH (1:5) & EC $\left(\mathrm{dS} \mathrm{m}^{-\mathbf{1}}\right)$ & $\mathrm{TC}(\%)$ & $\mathrm{NH}_{\mathbf{4}}-\mathbf{N}(\mathbf{m g} / \mathbf{k g})$ & $\mathbf{N O}_{3}-\mathbf{N}(\mathbf{m g} / \mathbf{k g})$ \\
\hline 5.04 & 4.85 & 1.34 & 44.24 & 41.51 \\
\hline \multicolumn{5}{c}{ EC; Electrical conductivity, TC; Total carbon. }
\end{tabular}

\section{Results}

For released $\mathrm{NH}_{4}-\mathrm{N}$, it was found that the $\mathrm{NH}_{4}-\mathrm{N}$ concentrations in all combination ratios of biochar pellet and pig manure were lower than that of the $100 \%$ pig manure compost pellet. The biochar pellet 2:8 ratio, biochar/compost displayed the highest difference compared with the pig manure compost pellet. After $150 \mathrm{~h}$ of retention time, not much difference could be seen between the 9:1 and the 8:2 biochar pellets (Figure 2).

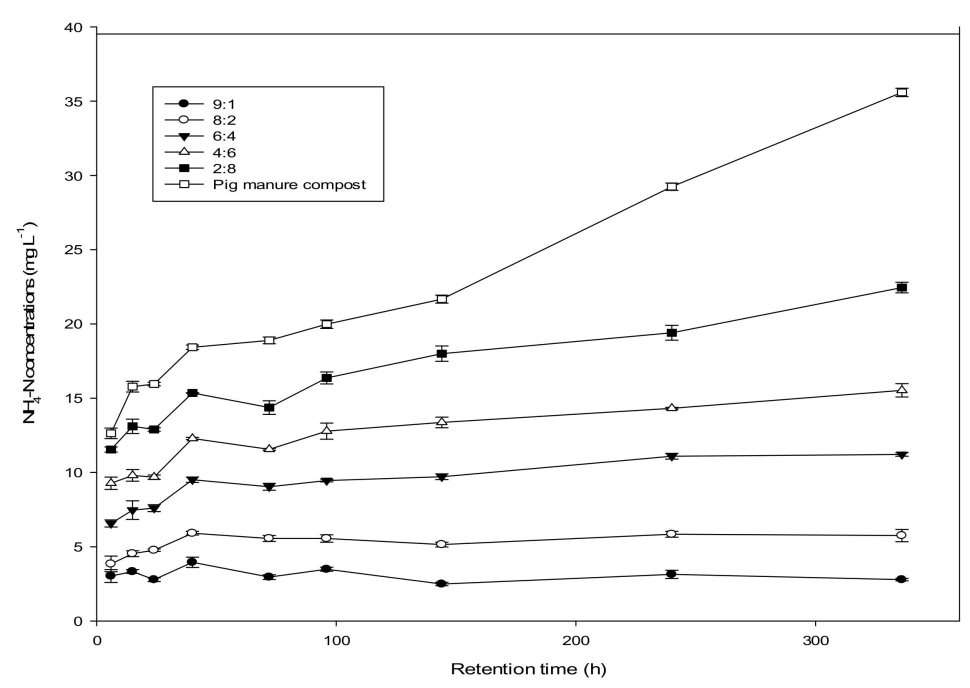

Figure 2. Changes of $\mathrm{NH}_{4}-\mathrm{N}$ concentrations in an aqueous solution with the retention times for biochar pellets with different compositional ratios of biochar/pig manure.

Therefore, it was observed that the biochar pellet, regardless of its combination ratio, could bond $\mathrm{NH}_{4}-\mathrm{N}$. The adsorption amount ranged from 7.75 to $3.1 \mathrm{mg} \mathrm{g}^{-1}$, and the removal rates decreased from 92.2 to $36.9 \%$ with decreasing biochar contents.

The results, as indicated in Figure 3, showed that increasing the quantity of the biochar content from 20 to $90 \%$ enhanced the removal rate at equilibrium and the adsorbed amount of $\mathrm{NH}_{4}-\mathrm{N}$ into the biochar pellet. It was observed that adsorption and removal rate of $\mathrm{NH}_{4}-\mathrm{N}$ by the biochar pellet lowered with decreasing biochar's ratios. However, it appeared that the maximum adsorption rate was observed for the 9:1 ratio of biochar pellet. The plot of Langmuir isotherm of $\mathrm{NH}_{4}-\mathrm{N}$ absorption on the biochar pellet is presented in Figure 4. The corresponding isotherm parameters are presented in Table 5. It was observed that the Langmuir adsorption capacity of the biochar pellet for $\mathrm{NH}_{4}-\mathrm{N}$ was $2.94 \mathrm{mg} \mathrm{g}^{-1}$. 


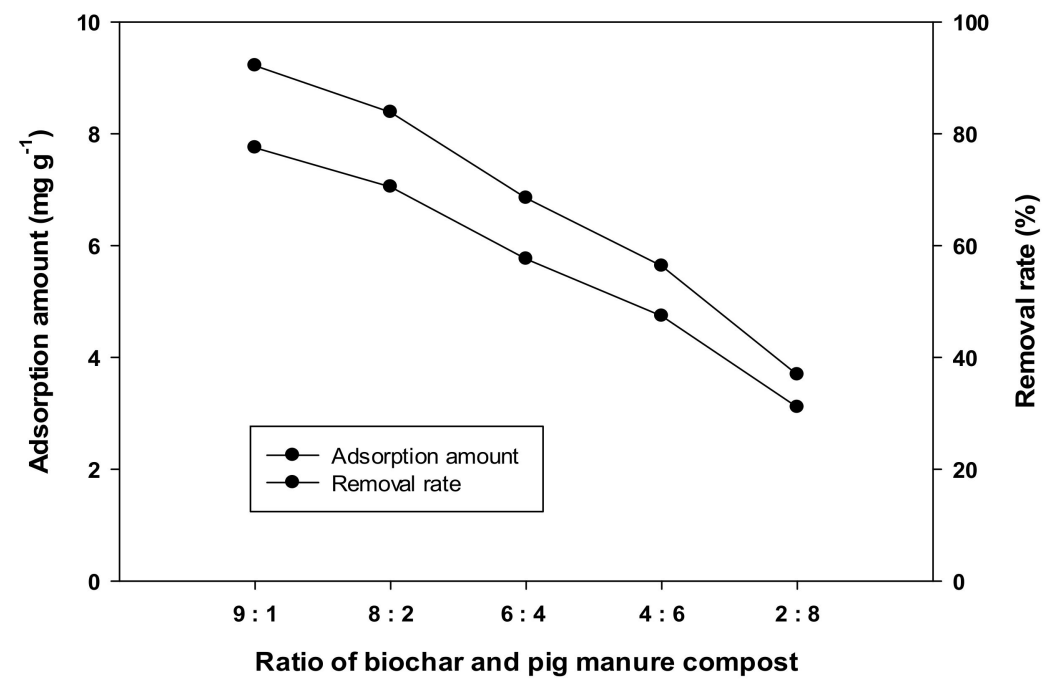

Figure 3. Variation of the adsorption amount and removal ratio of $\mathrm{NH}_{4}-\mathrm{N}$ for different ratios of biochar pellet, with different retention times.

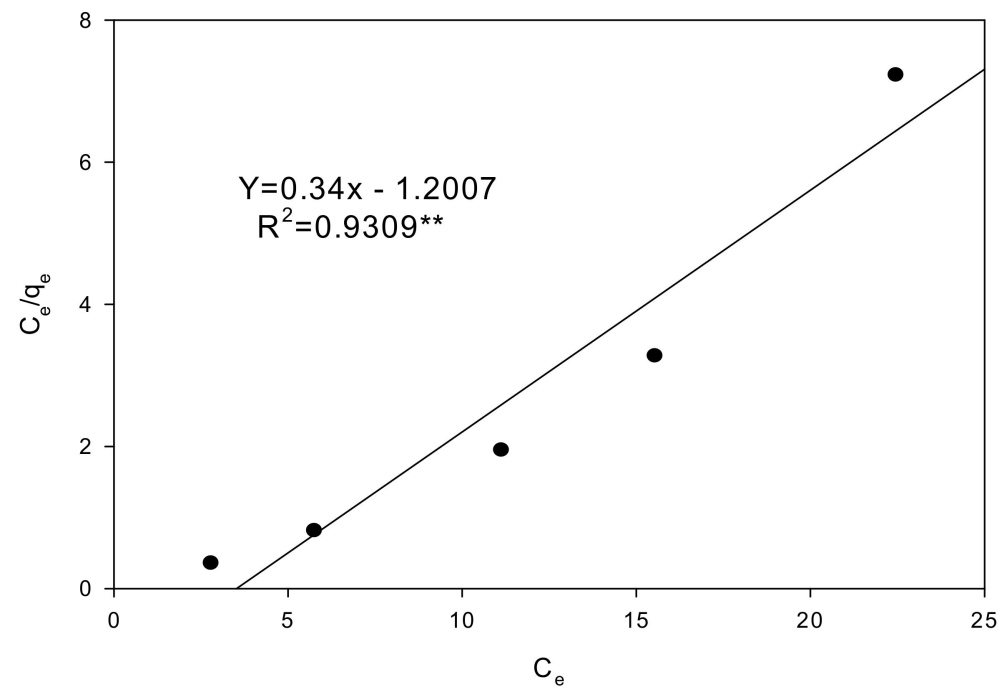

Figure 4. Langmuir isotherm plot of $1 / \mathrm{C}_{\mathrm{e}}$ versus $1 / \mathrm{q}_{\mathrm{e}}$ for $\mathrm{NH}_{4}-\mathrm{N}\left(\mathrm{q}_{\mathrm{e}}\right.$ is the amount of $\mathrm{NH}_{4}-\mathrm{N}$ adsorbed on the biochar pellet $\left(\mathrm{mg} \mathrm{g}^{-1}\right)$, and $\mathrm{C}_{\mathrm{e}}$ is the concentration of $\mathrm{NH}_{4}-\mathrm{N}$ in solution at equilibrium $\left(\mathrm{mg} \mathrm{L}^{-1}\right)$ ).

Table 4 shows the amount of $\mathrm{NH}_{4}-\mathrm{N}$ adsorbed at equilibrium $\left(\mathrm{q}_{\mathrm{e}}\right)$ at the slope and intercept, rate constants $\left(\mathrm{K}_{1}\right.$ and $\left.\mathrm{K}_{2}\right)$ of the kinetic models. The initial adsorbed amount $(\mathrm{h})$ was calculated as seen in Figure 5. It was calculated that the constant rate $\left(\mathrm{K}_{1}\right)$ of the pseudo first-order kinetic and $\mathrm{q}_{\mathrm{e}}$ ranged from 0.002 to $0.0019 \mathrm{~h}^{-1}$ and from 2.93 to $5.5 \mathrm{mg} \mathrm{g}^{-1}$, respectively, with correlation coefficient values of 0.778-0.949. For the pseudo-second-order model, it appeared that the constant rate $\left(\mathrm{K}_{2}\right)$ and $\mathrm{q}_{\mathrm{e}}$ ranged from 0.019 to $0.046 \mathrm{~h}^{-1}$ and from 2.09 to $4.65 \mathrm{mg} \mathrm{g}^{-1}$, respectively, with correlation coefficient values of 0.986-0.991 (Table 4). 
Table 4. Parameter calculated for the pseudo-first and second-order model from kinetic models.

\begin{tabular}{ccccccccc}
\hline \multirow{2}{*}{ Mixed Ratios } & \multicolumn{3}{c}{ Pseudo-First Order } & \multicolumn{3}{c}{ Pseudo-Second Order } & \multirow{2}{*}{${ }^{3}$ qe (exp.) } \\
\cline { 2 - 7 } & ${ }^{\mathbf{1}} \mathbf{K}_{\mathbf{1}}$ & ${ }^{\mathbf{2}} \mathbf{q}$ & $\boldsymbol{R}^{\mathbf{2}}$ & $\mathbf{K}_{\mathbf{2}}$ & $\mathbf{h}$ & $\mathbf{q} \mathbf{e}$ & $\boldsymbol{R}^{\mathbf{2}}$ & \\
\hline $9: 1$ & 0.0020 & 5.50 & $0.949^{* *}$ & 0.019 & 0.41 & 4.65 & $0.988^{* *}$ & $7.75^{*}$ \\
$8: 2$ & 0.0020 & 5.12 & $0.932^{* *}$ & 0.022 & 0.36 & 4.00 & $0.986^{* *}$ & $7.05^{*}$ \\
$6: 4$ & 0.0017 & 4.41 & $0.913^{* *}$ & 0.031 & 0.26 & 2.90 & $0.989^{* *}$ & 5.76 \\
$4: 6$ & 0.0018 & 3.97 & 0.851 & 0.046 & 0.19 & 2.02 & $0.991^{* *}$ & 4.74 \\
$2: 8$ & 0.0019 & 2.93 & 0.778 & 0.117 & 0.11 & 0.96 & $0.975^{* *}$ & 3.11 \\
\hline
\end{tabular}

${ }^{1} \mathrm{~K}_{1}$ : Pseudo-first-order kinetic constant of $\mathrm{NH}_{4}-\mathrm{N},{ }^{2} \mathrm{q}_{\mathrm{e}}$ : Adsorption amount from pseudo-first-order equation,

${ }^{3} \mathrm{q}_{\mathrm{e}}(\exp )$ : Adsorption amount from experiment data, ${ }^{* *}$ denotes significance at $1.0 \%$ and ${ }^{*}$ denotes significance at $5 \%$.

The initial adsorbed amount $(\mathrm{h})$ was calculated as seen in Figure 5. It appeared that the fastest adsorption of $\mathrm{NH}_{4}-\mathrm{N}$ was for the 9:1 combination ratio of biochar pellet in the kinetic model. It was also observed that the more the biochar contained in the biochar pellet, the greater the adsorption of $\mathrm{NH}_{4}-\mathrm{N}$.
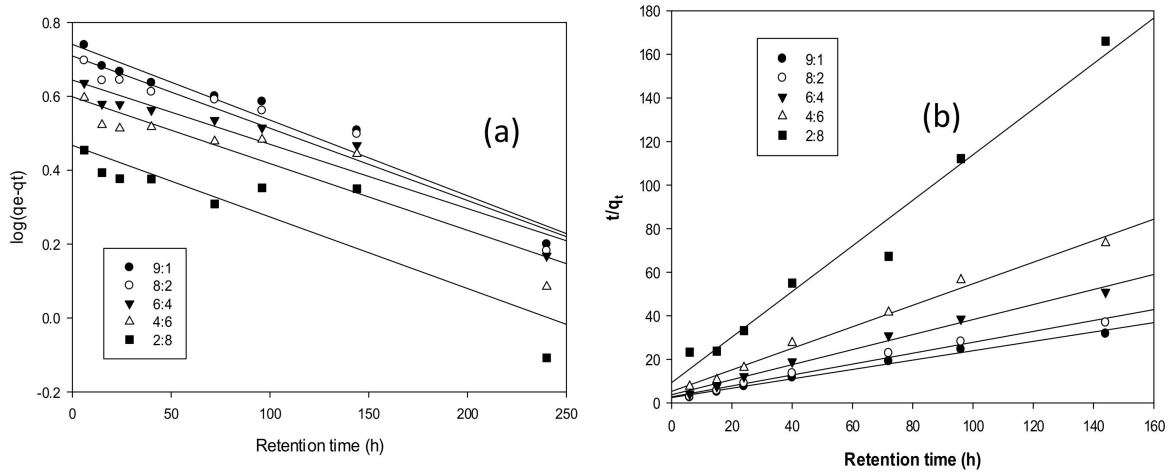

Figure 5. Pseudo-first-order kinetic plots (a) and pseudo-second-order kinetic plots (b) of $\mathrm{NH}_{4}-\mathrm{N}$ on different ratios of biochar pellets from rice hull ( $\mathrm{q}_{\mathrm{e}}$ is the adsorption amount at equilibrium $\left(\mathrm{mg} \mathrm{g}^{-1}\right)$, and $\mathrm{q}_{\mathrm{t}}$ is the adsorption amount at time $\left.\mathrm{t}\left(\mathrm{mg} \mathrm{g}^{-1}\right)\right)$.

Lettuce growth responses to the application of the biochar pellets with different amounts of pig manure compost are described in Figure 6. It was observed that the leaf biomass in the 9:1 mixture-treated plots (biochar/pig manure compost) significantly increased, approximately of 13\% compared with the control. The leaf biomass in plots undergoing other treatments was higher than that of the control.

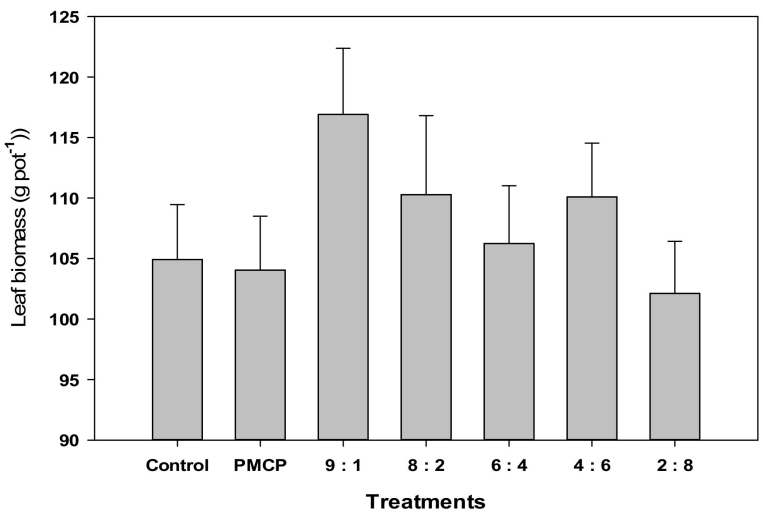

Figure 6. Growth responses of lettuce in the plots treated with biochar pellets with different ratios of biochar/pig manure compost. 


\section{Discussions}

\section{1. $\mathrm{NH}_{4}-\mathrm{N}$ Releasing Patterns of the Biochar Pellets}

The releasing patterns of $\mathrm{NH}_{4}-\mathrm{N}$ in deionized water of biochar pellets consisting of different ratios of biochar/pig manure were investigated. As shown in Figure 1, the concentration of $\mathrm{NH}_{4}-\mathrm{N}$ increased gradually in the combination of pellet mixed with biochar, as the retention time increased. It appeared that the binding of $\mathrm{NH}_{4}-\mathrm{N}$ to biochar increased with the pellets' wider surface area. However, for retention times greater than $150 \mathrm{~h}$, it was observed the $\mathrm{NH}_{4}-\mathrm{N}$ concentration abruptly increased. The retention time coinciding with the maximum release was considered as the equilibrium. The releasing concentrations of $\mathrm{NH}_{4}-\mathrm{N}$ from the biochar pellet in aqueous solution were almost constant after $250 \mathrm{~h}$ of retention time after equilibrium, except for the biochar pellet with a 2:8 ratio of biochar/pig manure.

\subsection{Adsorption and Removal Rates of $\mathrm{NH}_{4}-\mathrm{N}$ from the Biochar Pellets}

The biochar pellet $\mathrm{pH}$ is well known as an important factor related to the adsorption of ions. The $\mathrm{pH}$ for various combination ratios of biochar ranged from $\mathrm{pH} 8.8$ to 9.2 (Table 5). The biochar pellet $\mathrm{pH}$ increased with increasing biochar contents.

Table 5. Chemical properties of the various combination ratios of biochar pellet used.

\begin{tabular}{cccccc}
\hline Parameters & $\mathbf{2 : 8}$ & $\mathbf{4 : 6}$ & $\mathbf{6 : 4}$ & $\mathbf{8 : 2}$ & $\mathbf{9 : 1}$ \\
\hline $\mathrm{pH}(1: 20)$ & 8.8 & 8.9 & 9.0 & 9.1 & 9.2 \\
$\mathrm{EC}\left(\mathrm{dS} \mathrm{m}{ }^{-1}\right)$ & 1.4 & 1.2 & 1.3 & 1.2 & 1.0 \\
\hline \multicolumn{5}{c}{ Combination ratios of biochar/pig manure compost. }
\end{tabular}

The adsorption and removal rates of $\mathrm{NH}_{4}-\mathrm{N}$ for the biochar pellet are described in Figure 2. They also increased when both biochar contents and retention time were raised. In the application of pig manure compost, $5500 \mathrm{~kg} \mathrm{ha}^{-1}$ as recommended for corn culture, the releasing amount of $\mathrm{NH}_{4}-\mathrm{N}$ was estimated at $300 \mathrm{~kg} \mathrm{ha}^{-1}$ from the models (Table 2). Therefore, the adsorption amounts of $\mathrm{NH}_{4}-\mathrm{N}$ in the biochar pellets when applied in the corn field were estimated to range from 17.0 to $42.6 \mathrm{~kg} \mathrm{ha}^{-1}$, based on the observation values and regardless of the mixing ratios of the biochar pellets. The adsorption rates of $\mathrm{NH}_{4}-\mathrm{N}$ ranged from 5.7 to $14.2 \%$ in the corn field treated with the biochar pellets.

As for the removal rate of $\mathrm{NH}_{4}-\mathrm{N}$, it was the lowest at $36.9 \%$ for the pellet containing $20 \%$ of biochar, and was the highest at $92.2 \%$ for the pellet containing $90 \%$ of biochar. Regarding the dose-response relationship for the biochar, it increased with the removal rate and the adsorbed amount $\left(\mathrm{mg} \cdot \mathrm{g}^{-1}\right)$. This could be due to the increased area of the adsorption sites, as the solid surface increases in solution [18]. Similar results of adsorption using biochar and adsorbents for $\mathrm{NH}_{4}-\mathrm{N}$ have been described for ion-exchange resins [19], zeolites [20], and activated carbon [21]. This result implies that the biochar pellet can play an important role as an absorbent of $\mathrm{NH}_{4}-\mathrm{N}$ when applied in cropland.

\subsection{Adsorption}

Two isotherm models, Freundlich and Langmuir isotherm, were tested to study the adsorption characteristics of $\mathrm{NH}_{4}-\mathrm{N}$ on the biochar pellet. However, Freundlich isotherm was not fitted for this experiment, and, thus, the Langmuir isotherm was used. It was apparent that the Langmuir isotherm fitted the experimental data, suggesting the proper applicability of the Langmuir model to this system. Therefore, the adsorption amount of $\mathrm{NH}_{4}-\mathrm{N}$ on the biochar pellet applied in a corn field was estimated to be $16.2 \mathrm{~kg} \mathrm{ha}^{-1}$, using Langmuir isotherm. It is considered that the adsorption rate of $\mathrm{NH}_{4}-\mathrm{N}$ was estimated to be at $5.4 \%$ on the basis of releasing models (Table 2) in the corn field treated with the biochar pellets. 
It could be estimated that the adsorption values in the treated fields could be ranged from $8(3 \%)$ to $26.4(8.8 \%) \mathrm{kg} \mathrm{ha}^{-1}$, in case of applying the minimum and maximum Langmuir isothermal values of $\mathrm{NH}_{4}-\mathrm{N}$ adsorption.

An $R$ value greater than 1 indicates an unfavorable type of adsorption, while a value between 0 and 1 represents a favorable adsorption [22]. In this experiment, $R^{2}$ was 0.931 , and this value indicated that the biochar pellet favors the adsorption of $\mathrm{NH}_{4}-\mathrm{N}$, regardless of the ratios of biochar and pig compost (Table 6).

Table 6. Parameters calculated from the Langmuir isotherm model for the biochar pellet.

\begin{tabular}{cccc}
\hline $\mathbf{q}_{\mathbf{m}}{ }^{\mathbf{1}}$ & $\mathbf{b}^{\mathbf{2}}$ & $\boldsymbol{R}^{\mathbf{2}}$ & $\mathbf{R}_{\mathrm{L}}{ }^{3}$ \\
\cline { 1 - 2 } $\left.\mathbf{( m g ~ g}^{-\mathbf{1}}\right)$ & $\left(\mathrm{L} \mathrm{mg}^{-1}\right)$ & & \\
\hline 2.94 & 0.28 & $\substack{0.931 \\
* *}$ & 0.09
\end{tabular}

${ }^{1} \mathrm{q}_{\mathrm{m}}$ : maximum adsorption capacities of $\mathrm{NH}_{4}-\mathrm{N},{ }^{2}$ b: binding strength constant of $\mathrm{NH}_{4}-\mathrm{N},{ }^{3} \mathrm{R}_{\mathrm{L}}$ : dimensionless constant of Langmuir isotherm, ** denotes significance at $1.0 \%$ levels.

\subsection{Adsorption Kinetics}

Similar to the batch test, a kinetic experiment using $211.5 \mathrm{mg}$ of biochar pellet in $50 \mathrm{~mL}$ of deionized water was performed. The sorption of ammonium nitrogen was investigated for five combination ratios of biochar pellet, i.e., 9:1, 8:2, 4:6, and 2: 8, at $25^{\circ} \mathrm{C}$ and with aretention time ranging from $0.5 \mathrm{~h}$ to $250 \mathrm{~h}$. The consistency between the measured data and the predicted values from the model was expressed by the correlation coefficient $\mathrm{r}^{2}$. The relatively higher value is more applicable to the kinetics of $\mathrm{NH}_{4}-\mathrm{N}$ adsorption. The best selected kinetic models are based on both the coefficient $\left(\mathrm{r}^{2}\right)$ of linear regression and the calculated $\mathrm{q}_{\mathrm{e}}$ values. When the calculated $\mathrm{q}_{\mathrm{e}}\left(\mathrm{mg} \cdot \mathrm{g}^{-1}\right)$ was compared to the measured value $\left(\mathrm{q}_{\mathrm{e}}(\exp )\right)$, it was decided that, if the calculated $\mathrm{q}_{\mathrm{e}}$ was close in the range to the measuring value $\left(\mathrm{q}_{\mathrm{e}}(\mathrm{exp})\right)$, the data fitted well. Another judgement was considered for the coefficient value of regression $\left(R^{2}\right)$. The isotherm curves for each model are described in Figure 4 . It was calculated that the constant rate $\left(\mathrm{K}_{1}\right)$ of the pseudo-first-order kinetic and $\mathrm{q}_{\mathrm{e}}$ ranged from 0.002 to $0.0019 \mathrm{~h}^{-1}$ and from 2.93 to $5.5 \mathrm{mg} \mathrm{g}^{-1}$, respectively, with correlation coefficient values of 0.778-0.949. For the pseudo-second-order model, it appeared that the constant rate $\left(\mathrm{K}_{2}\right)$ and $\mathrm{qe}_{\mathrm{e}}$ ranged from 0.019 to $0.046 \mathrm{~h}^{-1}$ and from 2.09 to $4.65 \mathrm{mg} \mathrm{g}^{-1}$, respectively, with correlation coefficient values of $0.986-0.991$. The initial adsorbed amounts (h) ranged from 0.11 to $0.41 \mathrm{mg} \mathrm{g}^{-1} \mathrm{~min}^{-1}$. It was found that the correlation coefficient values $\left(R^{2}\right)$ for the pseudo-second-order models were higher than those for the pseudo-first-order model for the different biochar combination ratios. It can be assumed that some of the $\mathrm{NH}_{4}-\mathrm{N}$ adsorption in the biochar pellet could occur by chemisorption, with a better fit for the pseudo-second-order model [23].

\subsection{Plant Growth Responses to the Biochar Pellets}

The application of biochar pellets regardless of the biochar contents for lettuce cultivation could sequester soil carbon and mitigate the greenhouse gases without reduction of lettuce yield compared with the control plots treated with pig manure compost only. The lettuce yield in plots treated with biochar pellet that contained at least $40 \%$ biochar was higher than that of the control. It was considered that this might be due to the binding of $\mathrm{NH}_{4}-\mathrm{N}$ to biochar followed by slow releases during lettuce growth. However, these results need further study to explain why lettuce yields in the two treatments abruptly increased. Moreover, the application of biochar in the corn field for carbon sequestration did not inhibit corn growth, rather it increased the fresh weight of corn biomass, except for the application of pig manure compost [24]. Shin et al. [25] indicated that there was not a significant difference on plant height and fresh ear yield among the biochar treatments. 


\section{Conclusions}

It is necessary to study the adsorption characteristics of $\mathrm{NH}_{4}-\mathrm{N}$ on combinations of biochar pellet containing different amounts of pig manure compost with respect to carbon sequestration, for farming practices. The maximum adsorption rate observed was for the 9:1 ratio of biochar pellet/pig manure. For the removal rates of $\mathrm{NH}_{4}-\mathrm{N}$, the lowest rate at $36.9 \%$ was found for the pellet containing $20 \%$ of biochar, and the highest at $92.2 \%$ for the pellet containing $90 \%$ of biochar. The Langmuir adsorption capacity of the biochar pellet for $\mathrm{NH}_{4}-\mathrm{N}$ was $2.94 \mathrm{mg} \mathrm{g}^{-1}$. The fastest absorption of $\mathrm{NH}_{4}-\mathrm{N}$ was observed for the 9:1 combination of biochar pellet, as determined by kinetic models. It was observed that the higher the amount of biochar contained in the biochar pellet, the greater the adsorption of $\mathrm{NH}_{4}-\mathrm{N}$. The correlation coefficient values $\left(R^{2}\right)$ for the pseudo-second-order model were higher than those of the pseudo-first-order model for different biochar combination ratios. For the plant responses, it was observed that leaf biomass in 9:1 biochar/pig manure-treated plots increased more, by approximately at $13 \%$, compared with those in the control. In addition, the leaf biomass of other treatments was also higher than that of the control. This implies that the application of biochar pellet, regardless of the biochar content, is potentially useful to obtain fundamental data for $\mathrm{NH}_{4}-\mathrm{N}$ adsorption in in agricultural practices.

Author Contributions: J.S. conceived and designed the study. J.S., E.C., E.J., S.G.H., B.R., S.L. compiled the numerical tables and graphs and completed the writing of this paper. Finally, the writing was reviewed by J.S., B.R. All authors read and approved the manuscript.

Acknowledgments: This work was performed with the support of the "Cooperative Research Program for Agricultural Science \& Technology Development (Project No. PJ013814012018)", Rural Development Administration, Republic of Korea.

Conflicts of Interest: The authors declare no conflict of interest.

\section{References}

1. Ben-Iwo, J.; Manovic, V.; Longhurst, P. Biomass resources and biofuels potential for the production of transportation fuels in Nigeria. Renew. Sustain. Energy Rev. 2016, 63, 172-192. [CrossRef]

2. Brosowski, A.; Thrän, D.; Mantau, U.; Mahro, B.; Erdmann, G.; Adler, P.; Stinner, W.; Reinhold, G.; Hering, T.; Blanke, C. A review of biomass potential and current utilisation-Status quo for 93 biogenic wastes and residues in Germany. Biomass Bioenergy 2016, 95, 257-272. [CrossRef]

3. MIFAFF. Annual Statistics in Food, Agriculture, Fisheries and Forestry in 2009; Korean Ministry for Food, Agriculture, Fisheries and Forestry: Gwacheon, Korea, 2010.

4. Ding, Y.; Liu, Y.; Liu, S.; Li, Z.; Tan, X.; Huang, X.; Zeng, G.; Zhou, L.; Zheng, B. Biochar to improve soil fertility. A review. Agron. Sustain. Dev. 2016, 36, 1-18. [CrossRef]

5. Filiberto, D.; Gaunt, J. Practicality of biochar additions to enhance soil and crop productivity. Agriculture 2013, 3, 715-725. [CrossRef]

6. Awasthi, M.K.; Wang, Q.; Ren, X.; Zhao, J.; Huang, H.; Awasthi, S.K.; Lahori, A.H.; Li, R.; Zhou, L.; Zhang, Z. Role of biochar amendment in mitigation of nitrogen loss and greenhouse gas emission during sewage sludge composting. Bioresour. Technol. 2016, 219, 270-280. [CrossRef] [PubMed]

7. Kammann, C.I.; Schmidt, H.-P.; Messerschmidt, N.; Linsel, S.; Steffens, D.; Müller, C.; Koyro, H.-W.; Conte, P.; Stephen, J. Plant growth improvement mediated by nitrate capture in co-composted biochar. Sci. Rep. 2015, 5, 11080. [CrossRef] [PubMed]

8. Major, J.; Lehmann, J.; Rondon, M.; Goodale, C. Fate of soil applied black carbon: Downward migration, leaching and soil respiration. Glob. Chang. Biol. 2010, 16, 1366-1379. [CrossRef]

9. Shin, J. Carbon Sequestration and Nitrogen Transformation in Soil Cooperated with Organic Composts and Biochar during corn (Zea mays) Cultivation. J. Agric. Chem. Environ. 2015, 3, 96-101. [CrossRef]

10. Reza, M.T.; Lynam, L.G.; Vasquez, V.R.; Coronella, C.J. Pelletization of Biochar from Hydrothermally Carbonized Wood. Environ. Prog. Sustain. Energy 2012, 31, 225-234. [CrossRef]

11. Abdullah, H.; Wu, H. Biochar as Fuel: 1. Properties and Grindability of Biochars Produced from the Pyrolysis of Mallee Wood under Slow-Heating Conditions. Energy Fuels 2009, 23, 4174-4182. [CrossRef] 
12. Cantrell, K.B.; Martin, J.H., II. Poultry litter and switchgrass blending and pelleting characteristics for biochar production. Am. Soc. Agric. Biol. Eng. 2012, 57, 543-553.

13. Hagemann, N.; Joseph, S.; Schmidt, H.P.; Kammann, C.I.; Harter, J.; Borch, T.; Young, R.B.; Varga, K.; Taherymoosavi, S.; Elliott, K.W.; et al. Organic coating on biochar explains its nutrient retention and stimulation of soil fertility. Nat. Commun. 2017, 8, 1-11. [CrossRef] [PubMed]

14. Kulyk, N. Cost-Benefit Analysis of the Biochar Application in the U.S. Cereal Crop Cultivation; Center for Public Policy Administration Capstones, University of Massachusetts: Amherst, MA, USA, 2012.

15. Nadaroglu, H.; Kalkan, E.; Demir, N. Removal of copper from aqueous solution using red mud. Desalination 2010, 153, 90-95. [CrossRef]

16. Ho, Y.S.; Mckay, G. Sorption of dye from aqueous solution by peat. Can. J. Chem. Eng. 1998, 76, $822-827$. [CrossRef]

17. Na, C.; Park, H. Applicability of Theroretical Adsorption Models for Studies on Adsorption Properties of Adsorbents (II). Environ. Eng. Res. 2011, 33, 804-811.

18. Kizito, S.; Wu, S.; Kirui, W.K.; Lei, M.; Lu, Q.; Bah, H.; Dong, R. Evaluation of slow pyrolyzed wood and rice husks biochar for adsorption of ammonium nitrogen from piggery manure anaerobic digestate slurry. Sci. Total Environ. 2015, 505, 102-112. [CrossRef] [PubMed]

19. Sica, M.; Duta, A.; Teodosiu, C.; Draghici, C. Thermodynamic and kinetic study on ammonium removal from a synthetic water solution using ion exchange resin. Clean Technol. Environ. Policy 2014, 16, 351-359. [CrossRef]

20. Huang, H.; Xiao, X.; Yan, B.; Yang, L. Ammonium removal from aqueous solutions by using natural Chinese (Chende) zeolite as adsorbent. J. Hazard. Mater. 2010, 175, 247-253. [CrossRef] [PubMed]

21. Long, X.L.; Cheng, H.; Xin, Z.L.; Xiao, W.D.; Li, W.; Yuan, W.K. Adsorption of ammonia on activated carbon from aqueous solutions. Environ. Prog. 2008, 27, 225-233. [CrossRef]

22. Palanisamy, P.N.; Sivakumar, P. Kinetic and isotherm studies of adsorption of acid blue 92 using a low cost non- conventional activated carbon. Desalination 2009, 249, 388-397. [CrossRef]

23. Zhu, K.; Fu, H.; Zhang, J.; Lv, X.; Tang, J.; Xu, X. Studies on removal of $\mathrm{NH}_{4}-\mathrm{N}$ from aqueous solution by using the activated carbons derived from rice husk. Bioenergy 2012, 43, 18-25. [CrossRef]

24. Shin, J.; Kim, S.I.; Park, W.K.; Choi, Y.S.; Hong, S.G.; Park, S.W. Carbon sequestration in soil cooperated with organic composts and bio-char during corn (Zea mays) cultivation. J. Agric. Chem. Environ. 2014, 2, 151-155. [CrossRef]

25. Shin, J.; Choi, S.; Shin, J.H. Profit Analysis by Soil Carbon Sequestration with different Composts and Cooperated with Biochar during Corn (Zea mays) Cultivation Periods in Sandy Loam Soil. J. Agric. Chem. Environ. 2016, 5, 107-113. [CrossRef]

(C) 2018 by the authors. Licensee MDPI, Basel, Switzerland. This article is an open access article distributed under the terms and conditions of the Creative Commons Attribution (CC BY) license (http://creativecommons.org/licenses/by/4.0/). 